\title{
Effect of the beta adrenergic blocking agent propranolol on essential tremor
}

\author{
M. HILARY MORGAN, R. LANGTON HEWER, AND RAY COOPER
}

From the Neurological Research Unit, Frenchay Hospital, and the

Burden Neurological Institute, Bristol

SUMMARY A double blind trial of a single $40 \mathrm{mg}$ dose of the beta adrenergic blocking agent propranolol in the treatment of essential tremor produced significant reduction of tremor in four of five patients, but this effect was transient and had considerably diminished within four hours. A month's double blind clinical trial of propranolol, in a dose of $30 \mathrm{mg}$ three times a day, showed that the active drug gave statistically better results than placebo for the attenuation of tremor. The mode of action of propranolol in the reduction of essential tremor is probably a dual one, due both to blockage of peripheral beta receptors and to a central depressant effect.

Beta adrenergic blocking agents have been shown to reduce tremor in Parkinson's disease (Herring, 1964; Marsden, Gimlette, McAllister, Owen, and Miller, 1968), thyrotoxicosis, and in anxiety states. Herring (1964) showed that intravenous pronethalol diminished tremor of Parkinsonism in a controlled, but not double blind study. This drug was later withdrawn because of its carcinogenic properties in mice, but since then propranolol (Inderal, I.C.I.) has been introduced and found to be therapeutically more active. Owen and Marsden (1965) carried out a double blind clinical trial of propranolol and showed that it produced significant reduction of tremor in patients with Parkinsonism.

Emotional tension, and the administration of adrenaline, both increase the tremor of Parkinsonism (Barcroft, Peterson, and Schwab, 1952; Constas, 1962), but Owen and Marsden (1965) were able to show that the increase due to adrenaline could be abolished by propranolol. A reduction in the tremor of thyrotoxic and anxious patients after propranolol is presumably associated with this antagonistic action (Marsden, Foley, Owen, and McAllister, 1967; Marsden et al., 1968).

Essential tremor, which was first described by Dana in 1887, and Charcot in 1888, is thought to represent an exaggeration of normal tremor (Marshall, 1962). It is not usually a serious con- dition, as it progresses slowly, and the patients do not develop other neurological abnormalitie apart from some ataxia during voluntary move $\frac{?}{0}$ ment. Nevertheless, social embarrassment and disturbance of fine limb movements often cause distress, for which no specific therapy is avail able.

In view of the fact that propranolol alleviates the accentuation of tremor of Parkinsonism due to adrenaline, and that it is also of value in the tremor of thyrotoxic and anxious patients, when tremor is apparently an exaggeration of a physiological phenomenon (Graham, 1945; Redfearn, 1957; Marsden et al., 1968), a trial of this drug in the treatment of essential tremor was undertaken.

\section{METHODS}

Ten patients with an essential tremor were investigated, of whom six were male and four female. Their ages ranged from 41 to 77 years, with a mean of 54 years. The diagnosis of essential tremor was made if the patient exhibited a rhythmic tremor of the outstretched hands, at a frequency between 4 and $10 \mathrm{~Hz}$, but without evidence of other neurological abnormality apart from some intention tremor during the finger-nose test. All the patients had been referred by their general practitioners for treatment of their tremor, and care was taken to ascertain that none suffered from heart trouble, bronchitis, asthma, or recurrent diarrhoea. 
Two separate double blind trials were undertaken. For the first of these, five patients received a single $40 \mathrm{mg}$ oral dose of propranolol (Inderal, I.C.I.) or a similar matched placebo tablet on different occasions. The sequence of administration of these tablets, was arranged randomly before the trial and was not known to the assessor. At least three testfree days were allowed to elapse between each of the two trial days.

For the second clinical trial nine patients were included, of whom four had also taken part in the single dose trial. Assessments were undertaken at weekly intervals throughout a five week period, the first week being a baseline, no treatment, week. Subsequently, the patients were given either $30 \mathrm{mg}$ propranolol or placebo three times a day. The active drug was given for a week then changed to placebo, and the sequence repeated for the last two weeks. In some patients the order was placebo for a week then active drug for a week, and this sequence was repeated for the last two weeks. The allocation of patients to these two possible treatment sequences was random. This was again arranged before the trial without the knowledge of the assessor, who had merely to follow a coded instruction sheet when prescribing the tablets.

A check was kept on the number of tablets consumed between each visit, and only one week's supply was given to the patient each time. No other drugs were taken throughout the trial or for a week before it. Patients were also asked to avoid alcohol as it is known that this may reduce essential tremor.

Throughout the entire period of the examination and during the recording sessions care was taken to reduce the patients' anxiety by ensuring that they were always seen in the same room, by the same doctor (MHM), and that they had become thoroughly familiar with the test situation before the actual trial began. Each vatient was seen at approximately the same time every week.

Similar assessment procedures were employed for the single dose trial and for the longer clinical trial. Subjective evaluation was supplemented wherever possible by information obtained from relatives. Patients were asked standard questions at each visit and they were invited to state whether they felt that the tremor was definitely better, possibly better, unchanged, or worse, compared with their tremor without treatment. Assessments were made throughout the day, hourly for three hours before, and again hourly for four hours after the single $\mathbf{4 0 ~} \mathrm{mg}$ dose of propranolol. During the longer clinical trial the assessments were made throughout a period of one hour at weekly intervals. Objective clinical assessment of tremor was made with the patient's hand at rest, as well as extended against gravity. A visual evaluation of the degree of tremor was then possible. Specimens of handwriting and maze drawings (Gibson, 1964) were obtained on each occasion. An example of one such maze is shown in Fig. 1. For this test the patient is instructed to draw a line round the maze starting at the arrow and aiming for the outside by way of the maze pathway. Before the performance of this test the patient is instructed that he must not write over the thick black lines or over the circles. He is instructed to perform the test as rapidly as possible. Short cine films were also used to aid the clinical evaluation of tremor severity and to make it easier to compare performance on different occasions. The visual assessment, handwriting specimens, and maze drawing tests were each evaluated on a five point rating scale, in which grade four represented very severe disturbance of function or very severe tremor, grade one a mild disturbance or mild tremor, and grade 0 no disturbance.

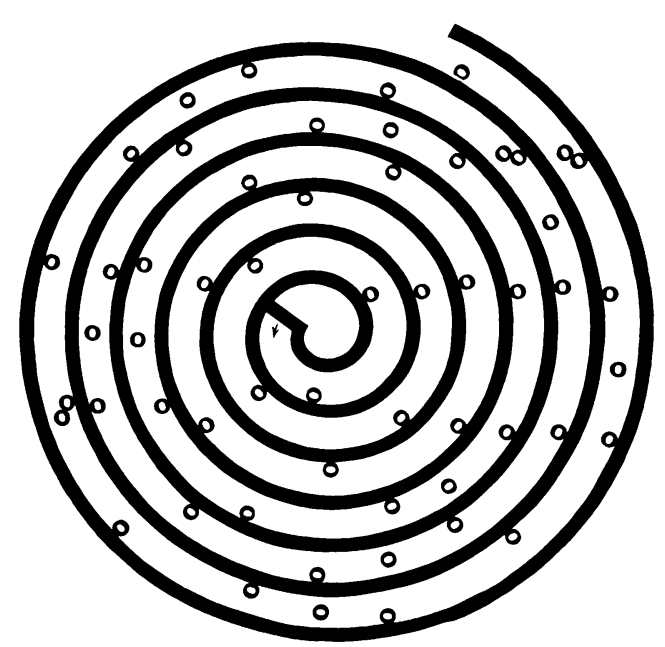

FIG. 1. An example of the Gibson Maze Test used in this study.

Tremor was recorded with a linear accelerometer (M.E.M.Electro Mechanisms Ltd., Slough, England), with a sensitivity of $\pm 6 \mathrm{G}$ weighing $25 \mathrm{~g}$, and size $3 \times 2.1 \times 1 \cdot 1 \mathrm{~cm}$. The accelerometer was strapped to the dorsal surface of the index finger, distal to the proximal interphalangeal joint. The active axis was in a plane at right angles to the finger, and tremor was recorded while the patient kept his arm extended with the forearm pronated. The resulting signal was recorded on an Elema-Schonander Mingograph. A 
standard gain was used for each recording, so that it was possible to compare any series of recordings obtained from one patient. Each tremor trace was stored simultaneously on computer tape, using a Linc 8 computer for later detailed analysis. Ten samples, each of eight seconds' duration, were estimated for each test situation. These were rectified and integrated, after the original traces had been balanced about a mean, to provide a numerical value for the amount of tremor activity in each test situation, a modification of the method of Morgan, Hewer, and Cooper (1972). Variability was overcome by averaging 10 samples in each situation, and comparison made by Student's $t$ test. The raw data were of normal distribution and no transformations were required.

\section{RESULTS}

SINGLE DOSE TRIAL Figure 2 shows the relative effects of active drug and placebo on the amount of tremor activity recorded two hours and four hours after an oral dose of $40 \mathrm{mg}$ propranolol.

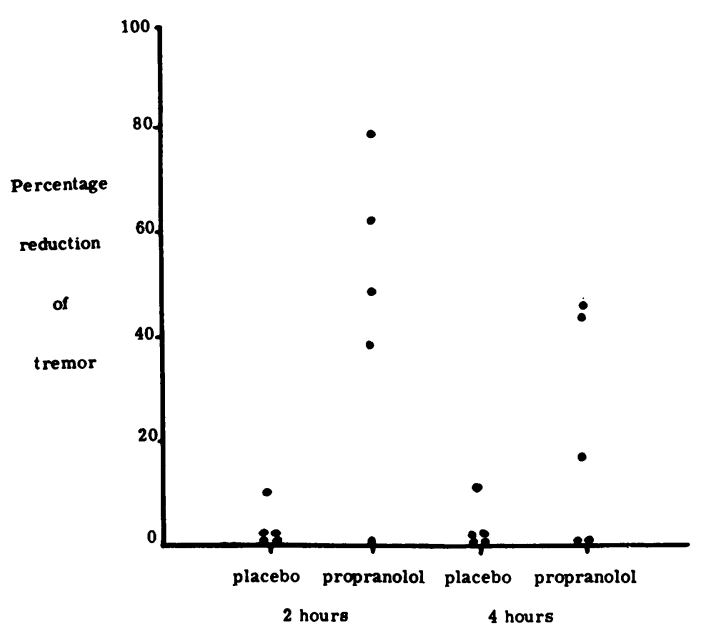

FIG. 2. The percentage reduction of tremor recorded two and four hours after $40 \mathrm{mg}$ propranolol or similar placebo. The measurements were made with an accelerometer, and tremor activity recorded as arbitrary units (see text for details).
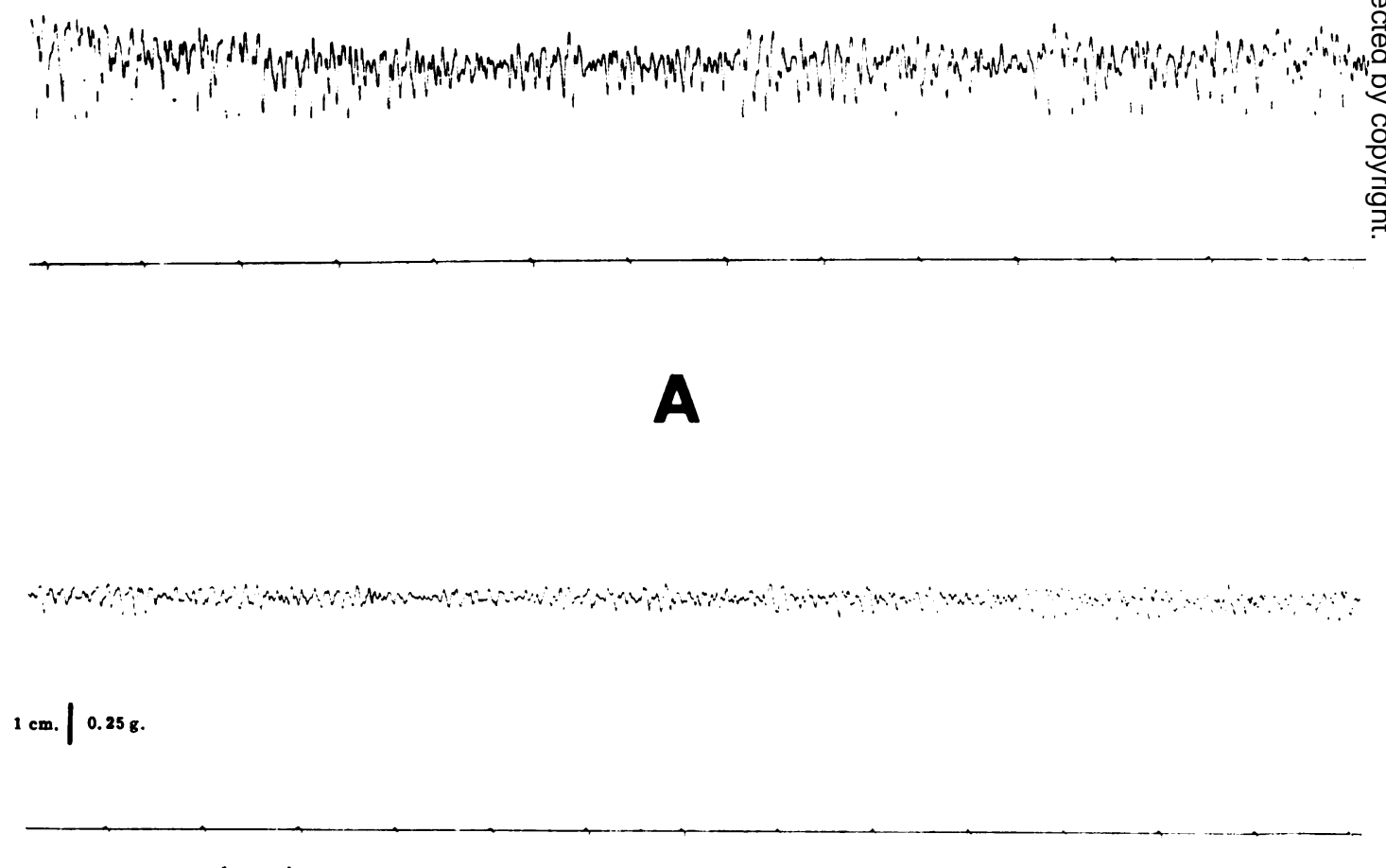

1 second

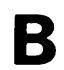

FIG. 3. Accelerometer recordings of tremor before and two hours after an oral dose of $40 \mathrm{mg}$ propranolol. 
No patients showed significant change after placebo. Four of the five patients showed a significant reduction in tremor two hours after this single dose $(P<0 \cdot 01)$. An example of two accelerometer tracings of tremor activity, recorded before, and two hours after propranolol is seen in Fig. 3. One of these four patients no longer showed any reduction in tremor activity four hours after treatment. In the remaining three patients the initial reduction had diminished between two and four hours after treatment. The change measured was found to be significant at the $1 \%$ level in three of the four patients who showed this effect.

PROLONGED TREATMENT TRIAL Seven patients completed the four weeks double blind trial. Clinical tests of tremor severity, based on visual assessment, handwriting specimens, and maze drawings, were assessed on a five point rating scale. In every case the total score was higher while on placebo than on propranolol (Table 1). All seven patients showed some reduction of their score comparing placebo with the 'no treatment' week but there was a greater reduction in score while on propranolol (significant at the $1 \%$ level). These results, while giving a highly significant result using Friedman's two way analysis of variance by ranking, are of course based on rating scales, with their inherent disadvantages. The differences in the

TABLE 1A

RESULTS OF CLINICAL EVALUATION OF TREMOR SEVERITY AND FUNCTIONAL DISABILITY AFTER PROPRANOLOL AND PLACEBO DURING THE MONTH'S TRIAL

\begin{tabular}{ccc}
\hline \multirow{2}{*}{ Patient } & \multicolumn{2}{c}{ Total score while on: } \\
\cline { 2 - 3 } & Propranolol & Placebo \\
\hline 1 & 14 & 18 \\
2 & 0 & 2 \\
3 & 12 & 14 \\
4 & 10 & 11 \\
5 & 6 & 13 \\
6 & 6 & 7 \\
7 & 3 & 5 \\
\hline
\end{tabular}

$\mathrm{X}_{\mathrm{r}}{ }^{2}=52, \mathrm{P}<0.01$ (Friedman's two-way analysis of variance by ranking).

Note: Maximum score for four weeks 48 . Low score represents good response, better limb function.
TABLE 1B

RESULTS OF CLINICAL EVALUATIONS OF TREMOR SEVERITY AND FUNCTIONAL DISABILITY WHILE ON PLACEBO AND PROPRANOLOL, COMPARED WITH BASELINE NO TREATMENT WEEK

\begin{tabular}{ccc}
\hline \multirow{2}{*}{ Patient } & \multicolumn{2}{c}{ Reduction in average score on: } \\
\cline { 2 - 3 } & Propranolol & Placebo \\
\hline 1 & 3 & 1 \\
2 & 2 & 1 \\
3 & 2 & 1 \\
4 & 1 & 0.5 \\
5 & 5 & 1.5 \\
6 & 2 & 0.5 \\
7 & 1.5 & 0.5 \\
\hline
\end{tabular}

$\mathrm{Xr}^{2}=430, \mathrm{P}<0.01$ (Friedman's two-way analysis of variance by ranking).

scores in some of the patients were not large in terms of absolute values.

There were significantly more reports of subjective improvement by patients who had been taking propranolol compared with reports after they had been receiving placebo. This difference was still significant if all reports of 'possible' improvement were included as negative reports (Table 2). Both patients who failed to show significant measurable reduction of tremor reported that they had noticed some improvement while undergoing treatment with the active tablets. In four patients the objective and subjective findings concurred, but one patient denied any useful benefit in spite of significant measurable reduction of tremor. Several patients commented that the improvement was variable, and two patients stated that anxiety continued to increase their tremor in spite of the treatment.

Tremor measurements using the accelerometer

TABLE 2

RESULTS OF SUBJECTIVE ASSESSMENTS OF TREMOR

\begin{tabular}{lcc}
\hline Subjective assessment & Placebo & Propranolol \\
\hline 'No improvement' & 12 & 2 \\
'Possibly better' & 0 & 3 \\
'Definitely better' & 2 & 9 \\
\hline
\end{tabular}

$2 \times 2 x^{2}$ test for 'no improvement' versus some improvement significant, with $\mathbf{P}<0.01 ; 2 \times 2 \chi^{2}$ test for 'definite improvement' versus none or possible, significant, $\mathrm{P}<$ 0.01 . 
TABLE 3

RESULTS OF TREMOR MEASUREMENTS AFTER PROPRANOLOL AND PLACEBO IN PATIENTS WITH ESSENTIAL TREMOR

\begin{tabular}{|c|c|c|c|c|}
\hline \multirow[t]{2}{*}{ Patient } & \multicolumn{2}{|c|}{$\begin{array}{l}\text { Amount of tremor in arbitrary } \\
\text { units for each of } 2 \text { weeks on: }\end{array}$} & \multirow{2}{*}{$\begin{array}{c}\text { Values of } \\
t \text { for } \\
\text { propranolol } \\
\text { versus } \\
\text { placebo }\end{array}$} & \multirow[t]{2}{*}{$\begin{array}{l}\text { Values } \\
\text { of } P\end{array}$} \\
\hline & Placebo & Propranolol & & \\
\hline \multirow[t]{2}{*}{1} & $\begin{array}{l}199 \pm 41 \\
343 \pm 110\end{array}$ & $\begin{array}{r}88 \pm 13 \\
161 \pm 48\end{array}$ & $\begin{array}{l}8 \cdot 2 \\
4 \cdot 8\end{array}$ & $\begin{array}{l}<0.01 \\
<0.01\end{array}$ \\
\hline & $\begin{array}{l}375 \pm 109 \\
183 \pm 34\end{array}$ & $\begin{array}{r}82 \pm 32 \\
122 \pm 51\end{array}$ & $\begin{array}{l}8 \cdot 2 \\
3 \cdot 2\end{array}$ & $\begin{array}{l}<0.01 \\
<0.01\end{array}$ \\
\hline 3 & $\begin{array}{l}552 \pm 114 \\
404 \pm 12\end{array}$ & $\begin{array}{l}526 \pm 162 \\
339 \pm 61\end{array}$ & $\begin{array}{l}0 \cdot 4 \\
3 \cdot 3\end{array}$ & $\begin{array}{l}\text { NS } \\
<0.01\end{array}$ \\
\hline 4 & $\begin{array}{r}140 \pm-51 \\
57 \pm 27\end{array}$ & $\begin{array}{l}75 \pm 19 \\
36 \pm 11\end{array}$ & $\begin{array}{l}3 \cdot 8 \\
2 \cdot 7\end{array}$ & $\begin{array}{c}<0.01 \\
t \text { between } \\
0.02 \text { and } 0.05\end{array}$ \\
\hline 5 & $\begin{array}{l}237 \pm 44 \\
219 \pm 33\end{array}$ & $\begin{array}{l}168 \pm 31 \\
119 \pm 17\end{array}$ & $\begin{array}{l}4 \cdot 0 \\
8 \cdot 5\end{array}$ & $\begin{array}{l}<0.01 \\
<0.01\end{array}$ \\
\hline 6 & $\begin{array}{l}98 \pm 23 \\
63 \pm 10\end{array}$ & $\begin{array}{l}66 \pm 14 \\
49 \pm 12\end{array}$ & $\begin{array}{l}3 \cdot 7 \\
2 \cdot 8\end{array}$ & $\begin{array}{l}<0.01 \\
<0.01\end{array}$ \\
\hline 7 & $\begin{array}{r}97 \pm 11 \\
140 \pm 18\end{array}$ & $\begin{array}{l}94 \pm 13 \\
72 \pm 8\end{array}$ & $\begin{array}{r}0.6 \\
11.0\end{array}$ & $\begin{array}{c}\text { NS } \\
<0.01\end{array}$ \\
\hline
\end{tabular}

Note: The values listed for tremor activity represent an average of 10 samples in each case, and are given with the appropriate standard deviation.

(Table 3) showed that the amount of tremor activity after treatment with propranolol was significantly reduced in four patients on both occasions $(P<0.01)$, while the remaining three patients showed a significant reduction after one of the two weeks treatment with the active drug. Two of these three patients showed no significant reduction during the first week on propranolol, but a significant reduction during the second week, while the third patient showed a significant reduction in the first week which persisted during the third week while on placebo and a further reduction was then noted after the last week on propranolol.

Comparison of the amount of tremor activity after treatment with propranolol with that of the baseline 'no treatment' week, showed that some reduction of tremor occurred in all subjects, except patient 5 . Five patients showed significant reduction of tremor for the two weeks while on propranolol; one further patient showed significant reduction for one of the two trial weeks, and another did not show any significant reduction. These results closely parallel those found in a comparison between propranolol and placebo treatment weeks.

SIDE-EFFECTS One patient had to be withdrawn from the month's trial after only two days treatment with the active tablet as she developed bradycardia and complained that she felt faint. One other patient withdrew after two weeks, stating that the pressure of his work did not allow him to attend hospital again, although he had initially agreed to cooperate for the entire month. He did not experience objective improvement in either of the two weeks, nor did tremor measurements reveal any significant difference between the active drugs and placebo. Two patients complained of lassitude and depression while receiving propranolol, another complained of diarrhoea, and another was noted to have bradycardia. While receiving placebo one patient complained of diarrhoea, and another of excessive sweating.

\section{DISCUSSION}

The beta adrenergic blocking agent propranolol reduces essential tremor, both in a single oral $40 \mathrm{mg}$ dose, and when given for a week in a dose of $30 \mathrm{mg}$ three times a day. A mean reduction of $46 \%$ after the single dose is comparable with the results reported by Marsden et al. (1965) who noted a mean reduction of $48 \%$ and $46 \%$ in anxious and thyrotoxic patients respectively. Owen and Marsden (1965) also noted a marked variability in the response of patients with Parkinsonism tremor to propranolol but in our small series of patients with essential tremor the response appeared to be more uniform. The dose employed for the present study was similar to that used by these authors, and was greater than the dose which Strang (1965) administered without success to a series of patients with Parkinsonism. It seems very likely that tremor reduction after propranolol is dose dependent in all these conditions, and it has been suggested that $90 \mathrm{mg}$ daily is at the lower limits of tremor controlling dosage (Owen and Marsden, 1965). Winkler and Young (1972) have also noted a significant reduction of essential tremor while patients were on a dose of $40 \mathrm{mg}$ propranolol three times a day and none of their patients reported significant side-effects. 
Our results also differ slightly from those reported by Herring (1964) who commented that pronetholol produced a prolonged response from six to 24 hours, in a series of patients with Parkinsonism. Measurements of essential tremor in the present study showed that the maximum effect occurred within two hours after a single $40 \mathrm{mg}$ dose, with a mean reduction of $46 \%$ and that the effect was less during the subsequent two hours, with a mean reduction of $21 \%$. This may be one explanation for the temporal variation in response which was reported by some of our patients, and which might therefore be overcome by prescribing four instead of three tablets daily.

The mode of action of propranolol in reducing essential tremor is probably due in part at least to peripheral blockage of beta adrenergic receptors. It has been suggested that the site of the receptors concerned with physiological tremor is in the forearm (Marsden et al., 1967). In the very few pathological studies of patients with essential tremor no definite organic lesion has been found which might be correlated with the appearance of tremor (Herskovits and Blackwood, 1969), and there appears to be no real argument against the theory that this condition is a functional rather than a structural disorder. If, as seems likely, essential tremor represents an exaggeration of normal tremor, then its alleviation by propranolol is presumably due to a blocking action at a similar peripheral site.

However, propranolol does have other pharmacological actions, for it is also a central nervous depressant (Murmann, Almirante, and Saccani-Guelfi, 1966). The central mechanism in the response of tremor to stress is uncertain, but it has been suggested that corticofugal impulses influence tremor (Jung and Hassler, 1960). Modification of central neuronal systems may therefore also play a part in the action of propranolol on essential tremor. Two patients in the present series who experienced a reduction in tremor also stated that they felt rather tired and depressed.

Although our results showed a significant reduction of essential tremor due to propranolol, it should be noted that the number of patients included in this study was small, and this must be viewed against the background of a known wide variation in the amount of spontaneous tremor exhibited by such patients. Nevertheless, it seems likely that propranolol provides a worthwhile form of treatment for essential tremor, and probably also for related disorders such as senile tremor.

We are grateful to Dr. R. R. Young who encouraged us to undertake this trial, also to Dr. P. F. C. Bayliss, of the Clinical Research Department, Imperial Chemical Industries Ltd., for supplying the tablets and for helpful discussions. Financial assistance was provided by the South Western Regional Hospital Board, from whom one of us is receiving a research grant (M.H.M.). We are grateful to Mrs. W. Clark for secretarial assistance.

\section{REFERENCES}

Barcroft, H., Peterson, E., and Schwab, R. S. (1952). Action of adrenaline and noradrenaline on the tremor in Parkinson's disease. Neurology (Minneap.), 2, 154-160.

Charcot, J. N. (1888). Encore la chorée chronique. Chorée chronique hémilatérale avec démence chez une femme de 49 ans-quelques remarques à ce propos sur le tremblement héréditaire et le tremblement sénile. In Leçons du Mardi à la Salpêtrière. Policliniques, 1887-1888, pp. 563-566. Delahaye: Paris.

Constas, C. (1962). The effects of adrenaline, noradrenaline, and isoprenaline on Parkinsonian tremor. Journal of Neurology, Neurosurgery, and Psychiatry, 25, 116-121.

Dana, C. L. (1887). Hereditary tremor, a hitherto undescribed form of motor neurosis. American Journal of Medical Science, 94, 386-393.

Gibson, H. B. (1964). The Spiral Maze; a psychomotor test with implications for the study of delinquency. British Journal of Psychology, 55, 219-225.

Graham, J. D. P. (1945). Static tremor in anxiety states. Journal of Neurology, Neurosurgery, and Psychiatry, 8, 5760.

Herring, A. B. (1964). Action of pronetholol on parkinsonian tremor. Lancet, 2, 892-894.

Herskovits, E., and Blackwood, W. (1969). Essential (familial, hereditary) tremor: a case report. Journal of Neurology, Neurosurgery, and Psychiatry, 32, 509-511.

Jung, R., and Hassler, R. (1960). The extrapyramidal motor system. In Handbook of Physiology; Section 1. Neurophysiology. Vol. 2, pp. 863-927. Edited by J. Field, H. W. Magoun, and V. E. Hall. American Physiological Society: Washington.

Marsden, C. D., Foley, T. H., Owen, D. A. L., and McAllister, R. G. (1967). Peripheral $\beta$-adrenergic receptors concerned with tremor. Clinical Science, 33, 53-65.

Marsden, C. D., Gimlette, T. M. D., McAllister, R. G., Owen, D. A. L., and Miller, T. N. (1968). Effect of $\beta$ adrenergic blockade on finger tremor and Achilles reflex time in anxious and thyrotoxic patients. Acta Endocrinologica, 57, 353-362.

Marshall, J. (1962). Observations on essential tremor. Journal of Neurology, Neurosurgery, and Psychiatry, 25, 122-125.

Morgan, M. H., Hewer, R. L., and Cooper, R. (1972). A method of recording and analysing intention tremor. Brain, 95, 573-578. 
Murmann, W., Almirante, L., and Saccani-Guelfi, M. (1966). Central nervous system effects of four $\beta$-adrenergic receptor blocking agents. Journal of Pharmacy and Pharmacology, 18, 317-318.

Owen, D. A. L., and Marsden, C. D. (1965). Effect of adrenergic $\beta$-blockage on Parkinsonian tremor. Lancet, 2 , $1259-1262$.

Redfearn, J. W. T. (1957). Frequency analysis of physio- logical and neurotic tremors. Journal of Neurology, Neurosurgery, and Psychiatry, 20, 302-313.

Strang, R. R. (1965). Clinical trial with a beta-receptor antagonist (propranolol) in Parkinsonism. Journal of Neurology, Neurosurgery, and Psychiatry, 28, 404-406.

Winkler, G. F., and Young, R. R. (1972). The control of essential tremor by propranolol. Transactions of the American Neurological Association, 96, 66-68. 